\title{
Review of The Open Door Collective: The Workforce Basic Skills Resources Collection
}

Johan E. Uvin, Institute for Educational Leadership

The Open Door Collective (ODC) is a membership-driven, web-based resource portal for professionals in adult education, social services, and poverty reduction who have expertise in connecting adult basic skills education to employment and training, health care, and family and social services. Practitioners are the primary audience with researchers and policy makers being the secondary audience. This review will first provide an overall description and review of this portal, before exploring in depth an example of a resource found in the ODC.

\section{Why Does It Exist?}

ODC's mission is to help adult basic skills advocates create common cause with advocates for other issues (health, employment, incarceration, libraries, etc.) in order to build an integrated approach to ending poverty. Under the motto of "Opening the Door to Opportunity for Everyone," the ODC is dedicated to reshaping
U.S. society to have dramatically less poverty and economic inequality and more civic engagement and participation in all our society has to offer. Members of the ODC believe that adult basic skills education and lifelong learning programs can help open the doors of opportunity for everyone to healthier, more prosperous and satisfying lives and are committed to building an economic and political environment that supports innovative policies, programs and investment for developing the basic skills of all adults. The website includes a transparent statement of beliefs that illustrate this overall commitment.

\section{Who Leads It?}

The work of the ODC is overseen by a Steering Committee that consist of seven leading practitioners, policy makers, and researchers in the field of adult learning: John Comings, Eric Nesheim, Margaret Peterson, Steve Reder, David Rosen, Jen Vanek, and Gwenn Weaver. 


\section{What Does It Do?}

\section{Advocacy Issues Groups}

The ODC operates nine advocacy issues groups, which are the engines of ODC's efforts. These groups produce advocacy papers, presentations, and videos that set out the common cause within each ODC issue group. The issue groups are: Affordable Housing; Labor and Workforce Development; Public Libraries and Adult Basic Skills; Digital Inclusion; Health and ABE; Safety Net Services Advocacy; Criminal Justice Reform; Immigrant and Refugee Education and Integration; and Public K-12 Education and Intergenerational Literacy.

\section{Resources}

The website includes different types of resources.

- Newsletters. There is a seasonal newsletter of which three issues have been published and posted to date. The newsletter provides updates on key activities of the ODC.

- Papers. The second type of resources is the collection of ODC papers. Each of the papers provides the reader with a quick overview of what the current challenges and opportunities are and provide useful concrete examples of practices and policies the paper intends to promote as solutions to the issue. The papers cover a broad range of issues including: crimmigration (criminal justice-immigration), the role of basic skills in workplace advancement, the relationship between basic skills and public safety net, health, and incarceration, as well as critical cross-sectoral partnerships between adult basic education and health organizations, public libraries, and immigrant integration organizations.

- Topical Resource Collections. The third type of resources are topical resource collections.
There are four resource collections: Immigrant and Refugee Integration Resources, Criminal Justice and Adult Education Resources, Health Literacy in ABE Resources, and Workforce Basic Skills Resources. Each of these four resource collections presents content that was selected and curated, when necessary, by members of the associated ODC Issues Group.

\section{What Do the Topical Resource Collections Offer? An Example: Workforce Basic Skills Resources}

The Workforce Basic Skills Resources collection has two main parts to it: "Can-Do" Guides for Stakeholders and An Archive of Work-Related Basic Skills. The ODC Labor and Workforce Development Issues Group is developing a series of "Can-Do" Guides aimed at various stakeholders (e.g., employers, labor unions, prisoner re-entry agencies, universities, and others). Each guide explains why adult basic skills are important for the individuals with whom that stakeholder works (e.g., employees, union members, former inmates) and how that stakeholder can work with adult basic education providers to strengthen and expand basic skills development services in their community and state. The guides are based on experience and research in collaborative efforts with various stakeholder groups. Four guides have been produced to date:

- What Forward-Thinking Employers Can Do to Strengthen the Basic Skills of Our Workforce

- What Labor Educators Can Do to Strengthen the Basic Skills of Our Workforce

- What Re-Entry Services Can Do to Strengthen the Basic Sills of Former Inmates

- What Universities Can Do to Strengthen U.S. Adult Basic Skills Efforts 
An Archive of Work-Related Basic Skills Resources is a 38-page annotated mix of approximately 125 recent and not-so-recent resource materials related to work-related adult education. Dr. Paul Jurmo created the archive and organized the resources around 10 topical areas:

- Work-Readiness, College Transition, and Career Pathways for Job Seekers: Program Models and Practices;

- Work-Readiness for Particular Industries;

- Workplace Education for Incumbent Workers: Program Models and Practices;

- Tools for Assessing Worker Basic Skills;

- Tools for Program Planning and Evaluation;

- Work-Related Basic Education in the U.S.: Local, State, and National Policy;

- Interpretations of How to Make Workplace Education Relevant and Effective;

- Employer Perspectives;

- Labor Union Perspectives; and

- International Perspectives.

The purpose of the archive is to bring together in one place select work-related basic skills resources that have influenced worker education over the last 30-40 years. Objectives include informing newcomers to the field as well as those who have been in the field. The intended audience is broad and varied and includes teachers/facilitators, program designers and administrators, curriculum developers, federal, state, and local policy makers, researchers and evaluators, and critical partners in business, labor, and industry about basic skills education at and for work. The scope of the archive is broad and comprehensive including resources with hands-on design, implementation, teaching, and evaluation ideas, sector-based curriculum resources, policy and system resources, research and evaluation documents, descriptions of pertinent discussion groups, learning communities and communities of practice, links to journals, trade publications, and various newsletters, and so forth.

The author's perspective is best described in two ways. First, the reader/user should be aware that Jurmo is an advocate for worker-centered and participatory education. His views align with those of the ODC Issues Group that views "worker basic education as a tool to help workers attain, perform, and advance in family-sustaining employment" (OCD, 2019). Second, Jurmo believes that it is important to not just include resources that reflect worker-centered approaches but to give an overview of the different approaches and philosophies about how to approach the skills development of adult workers. As the website states, "[...] while most of these resources support a "contextualized" approach to work-related basic education, they are not unanimous in the particular contextualized applications they focus on nor in how they develop and run their programs" (OCD, 2019).

\section{What Specific Resources Are Included? Two Examples}

To illustrate the nature of the resources included in the archives, below are two examples. One example is a recent resource. The second example is an older resource. The examples were chosen because they speak to the way that work-related basic skills issues have evolved from a program paradigm to a career pathway programs and systems paradigm. The first example provides a state-of-the art view of research, policy, and practice issues in career pathways today. The second example looks at the specific role career awareness can and needs to play in the $\mathrm{ABE}$ and ESOL classroom. It is a very practical illustration of a practice that learners need and want but programs, on average, do not tend to provide. 


\section{FIRST EXAMPLE}

Special Issue on Career Pathways (COABE Journal, 2018). This special issue of the journal of the Coalition on Adult and Basic Education contains 13 articles on various aspects of adult education's role in career pathway initiatives. As for purpose, the articles together provide a 360-degree view of the history and current stateof-the-art in adult career pathways with a welcome emphasis on the perspective of the adult learning field. The objective of this special issue is to inform practitioners, policy makers, and funders with an interest in adult career pathway programs and systems with articles that focus on research, practice, and technology. In addition, six articles are grouped as a Forum discussion and highlight gaps in current practice (e.g., career awareness) and feature emerging, promising practices (e.g., guided pathways). The perspectives of the authors reflect a deep interest in, expertise with, and commitment to advancing the spread of career pathway programs, practices, and systems.

Given the central role of career pathways in the Workforce Innovation and Opportunities Act and the Strengthening Career and Technical Education for the $21^{\text {st }}$ Century Act, these perspectives are useful for anyone, from the classroom to the board room. The articles taken together provide newcomers to career pathways with historical context, a sense of current strengths and challenges in practice, research, and policy, and a preview of the emerging innovations in programming, policy, and funding. The ideas developed in each of the articles are articulated well, are adequately developed, and grounded in the relevant evidence base for the topics addressed. The layout is inviting and style and register of the articles are appropriate for both an expert and layperson audience, as the language is clear, accessible and straightforward.
It would be valuable to have this resource featured in the archive as one of the top most recent resources for anyone with an interest in how career pathway programs and systems can change the odds for adult learners and create a pathway to economic mobility and prosperity.

\section{SECOND EXAMPLE}

\section{Integrating Career Awareness into the $\mathrm{ABE}$} \& ESOL Classroom: Curriculum Guide (National College Transition Network, and Massachusetts System for Adult Basic Education

Support, 2009). The purpose of this resource is to provide information and guidance on how to integrate career awareness in the $\mathrm{ABE}$ and ESOL classrooms. The objective is to help adult education teachers and counselors guide adult learners through a comprehensive career planning process that promotes a full range of life skills. The scope of the resource is similar to what is typically found in curriculum guides. The guide begins with a three-page "How to Use this Guide." The curriculum is divided into four sections: cultural context for career awareness; self-exploration (skills, values, experience, interests, education); occupational exploration (occupational and job profiles, informational interviews, career and job fairs, and labor market information); and career and education planning (decision making, goal setting, college success skills, and action planning). Each section is divided into lessons. Each lesson outlines the topic learning objectives, materials needed, vocabulary, and extension activities. The Curriculum Guide provides adequate guidance while allowing flexibility to adapt to one's context. For instance, the guide includes handouts that practitioners can use as they are or modify them to meet the needs of their classrooms. The perspective of the authors reflects a learner-centered approach. 
This resource successfully accomplishes its objective of guiding teachers and counselors through a curriculum that allows adult learners to experience a comprehensive career planning process that promotes a full range of life skills. The materials and activities reflect that the authors are knowledgeable about issues of career awareness, career exploration, and career planning. The Curriculum Guide is presented in a highly accessible style. Navigating the guide is easy and intuitive.

This resource makes a significant contribution to theory, research, or practice in adult basic education and literacy. As indicated in the review of the first example (i.e., the Special Issue of the COABE Journal featuring career pathways), career awareness, exploration, and goal setting are the missing link in adult education practice. This resource shows practitioners in a handson manner how to bridge that gap in their own classrooms and counseling practices. The ODC should actively promote this resource so that more practitioners can integrate these much-needed services into their programs and practices.

\section{How Useful Is It? A Critical Evaluation}

The archive succeeds at its objectives of informing a broad audience including newcomers and more seasoned professionals in the field of work-related basic skills practice and policy. The archive has over 125 resources presented in an appropriate style and format for the intended audiences. The number of resources, however, can feel overwhelming at first and finding one's way through the resources can be challenging. While resources are grouped in 10 categories, organization can be improved. The challenge is not that the presentation of the resources is not clear. The challenge is that, with the exception of the 10 broad categories, the reader/user - particularly the newcomer user - is not offered much navigation or resource evaluation assistance.

All the intended audiences stand to benefit greatly from the resources included in the archive. The resources - depending on the roles, experience, goals, and needs of the audience - can be useful in instruction, curriculum development, program design, policy development and systems reform, and research and evaluation design. The greatest contribution the archive makes to theory, research, or practice in work-related adult basic education and literacy is that it is a single stop, "go-to" collection of past and current resources for work-related basic skills issues with direct links to most resources so that the user in two clicks can get to the specific information he or she needs.

It is important for the reader/user to be aware that this archive brings together resources that reflect different approaches and philosophies about how to approach the skills development of adult workers. The user should be mindful of the fact that the resources include both resources that reflect ODC's advocacy for worker-centered education that views "worker basic education as a tool to help workers attain, perform, and advance in family-sustaining employment" (OCD, 2019) and resources that reflect different perspectives and approaches that are less worker-centered. One consideration for future revisions to the archive is to indicate which resources feature workercentered approaches and practices and which ones do not.

\section{What Are the Main Takeaways about the ODC?}

The ODC is a much-needed and growing "go-to place" for advocates, practitioners, researchers, and policy makers who want to work on and advocate for adult learner issues using a cross- 
sectoral approach. As more members join and contribute resources, the ODC will continue - and needs - to evolve so that the resource collections, the ODC papers, and the newsletters will increase both in quantity and relevance. As the Steering Committee provides oversight, greater congruity between the various approaches used by the Issues Groups in designing their collections and addressing the variability in the extent to which content is evaluated and curated will enhance both the usefulness, attractiveness, and the navigation and use of the resources and the site.

\section{References}

Open Door Collective (January 2019), Workforce Basic Skills Resources. Retrieved on May 7, 2019 from http://www.opendoorcollective.org/workforce-basic-skills-resources.html 